\title{
PENDAMPINGAN PEMBUATAN BAHAN AJAR BERBASIS ETNOMATEMATIKA UNTUK GURU MATEMATIKA DI INDONESIA
}

\author{
Somakim ${ }^{1}$, Yusuf Hartono ${ }^{1}$, Indaryanti ${ }^{1}$, Jeri Araiku ${ }^{1}$ \\ ${ }^{1}$ Universitas Sriwijaya, Palembang, Indonesia \\ jeriaraiku@fkip.unsri.ac.id
}

\begin{abstract}
Abstrak: Kegiatan pengadian kepada masyarakat (PkM) ini bertujuan untuk mendampingi guru dalam membuat bahan ajar matematika berbasis etnomatematika dan mengetahui respon peserta terhadap kegiatan tersebut. Metode yang digunakan adalah service learning yang terbagi menjadi dua kegiatan yaitu synchronous dan asynchronous. Anchronous terdiri atas penyampaian materi dan presentasi, sedangkan asynchronous berupa bimbingan pembuatan bahan ajar. Peserta yang mengikuti kegiatan PkM ini adalah sebanyak 408 guru matematika yang menghasilkan sebanyak 78 buah bahan ajar setelah revisi. Hasil pengabdian ini menunjukkan lima kesalahan yang dilakukan oleh guru matematika dalam menuliskan bahan ajar berbasis etnomatematika antara lain: (1) bahan ajar yang dibuat tidak sesuai template yang ditentukan, (2) bahan ajar tidak memanfaatkan filosofi/nilai budaya, namun hanya melihat bentuk objek, (3) bahan ajar tidak didasarkan pada budaya tertentu, (4) materi dan langkah pembelajaran tidak sesuai dengan filosofi budaya yang diangkat, dan (5) kegiatan tidak dirancang dengan baik dan berpotensi plagiat. Respon peserta terhadap kegiatan dapat dikategorikan sangat baik $(4,55)$, sedangkan pengetahuan peserta mengenai etnomatematika dan kesulitan yang mungkin dihadapi peserta dalam membuat dan menerapkan bahan ajar berbasis etnomatematika di kelas tergolong baik, dengan nilai rata-rata masing-masing 3,9. Hal yang masih perlu diperhatikan oleh guru matematika adalah meluangkan lebih banyak waktu dalam mengeksplorasi nilai budaya sehingga filosofi dari budaya tersebut sesuai dengan konteks materi yang akan diajarkan. Guru juga perlu meningkatkan kemampuan dalam membuat dan menerapkan bahan ajar berbasis etnomatematika dalam proses pembelajaran matematika.
\end{abstract}

Kata Kunci: etnomatematika, pembuatan bahan ajar, pengabdian kepada masyarakat, matematika

\begin{abstract}
This community service program (PKM) aims to assist teachers in designing ethnomatematics-based mathematics teaching materials and examine participants' responses to the program. The method used is service learning in the form of synchronous and asynchronous. The first included presentations and content discussions, while the latter was to guide the teachers design teaching materials. There were 408 mathematics teachers participated in this program which resulted in 78 revised teaching materials. There were five mistakes made by the mathematics teachers in designing the ethnomathematics-based teaching materials: (1) it did not comply the specified template, (2) it did not acknowledge cultural philosophies/values, but only refer to the shape of the object, (3) it did not adopt a specific culture, (4) the materials and learning steps were not in accordance with the cultural philosophy used, and (5) the activities were not well designed and have the potential for plagiarism. Participants' responses to the program can be categorized as very good (4.55), while the participants' knowledge of ethnomatematics and the difficulties that participants may face in making and applying ethnomatics-based teaching materials in the classroom are classified as good, whereas each indicators has the average of 3.9. To the teachers need to spend more time exploring culture so that the philosophy of the culture is in accordance with the material to be taught. Also, the teachers should improve their ability to create ethnomathematical-based teaching materials and apply it in the instructional practices.
\end{abstract}

Keywords: ethnomatematics, designing teaching materials, community service, mathematics 


\section{Pendahuluan}

Perkembangan ilmu pengetahuan dan teknologi tidak terlepas dari eksistensi matematika (Nurhasanah, Kusumah, \& Sabandar, 2017; Young, 2017). Oleh sebab itu, membangun dan mengaplikasikan konsep-konsep matematis berdasarkan situasi masalah nyata merupakan bagian integral dari proses belajar siswa (Tanujaya, Prahmana, \& Mumu, 2017). Pada kenyataannya, matematika masih dilihat sebagai hal yang jauh dari kehidupan manusia (Prahmana \& Kusumah, 2016). Banyak siswa menganggap matematika tidak berhubungan dan tidak berguna untuk kehidupan mereka (Kusuma, Dewanto, Ruchjana, \& Abdullah, 2017). Hal ini menyebabkan mereka tidak dapat merasakan manfaat dari matematika. Oleh sebab itu, pendidikan matematika harus membantu memelihara pemahaman mengenai bagaimana matematika diaplikasikan dalam masyarakat yang dikendalikan oleh teknologi (Brand \& Chernoff, 2015). Matematika sekolah perlu untuk menjadi lebih inklusif terhadap matematika yang ditemukan di lingkungan siswa (Brand \& Chernoff, 2015). Salah satu teori yang menganut prinsip keterkaitan matematika dengan lingkungan siswa adalah etnomatematika.

Etnomatematika adalah matematika yang diterapkan antara lain oleh kelompok budaya tertentu, kelompok petani, anak-anak dari kelas masyarakat tertentu, dan kelas professional (D’Ambrosio, 1985; Gerdes, 1994). Ascher (1991) memperkenalkan dua komponen dalam menjelaskan etnomatematika. Pertama istilah "presentasi" yang berarti etnomatematika tidak hanya berada pada tingkat implisit atau sekedar gagasan, tetapi juga secara eksplisit dipraktikan dalam kenyataan. Kedua, Ascher (1991) menggunakan istilah "kelompok tradisional" karena keinginannya untuk memasukkan kelompok budaya yang telah secara jelas menyajikan matematikanya. Jenis budaya yang bisa dieksplorasi antara lain simbol matematis, perhitungan, hasil kerajinan, desain bangunan, dan cara khusus untuk menalar dan menyimpulkan (Francois, 2012; Arisetyawan, Suryadi, Herman, Rahmat, \& No, 2014). Belajar matematika dengan etnomatematika memiliki beberapa manfaat, antara lain mengurangi sifat abstrak dari belajar matematika (Achor, Imoko, \& Uloko, 2009), menghargai siswa lain yang memiliki budaya yang berbeda (Garegae, 2008), membangun pengetahuan siswa dengan membawa budaya dan sejarahnya untuk meningkatkan nilai dan budaya tersebut (Jenni, 2007), dan meningkatkan sikap positif terhadap matematika (Leng, 2006). Pengembangan bahan ajar berbasis etnomatematika ini sangat tepat untuk dipraktikkan di Indonesia karena Indonesia merupakan negara yang kaya akan budaya. Banyak hasil budaya, misalnya berbagai bentuk rumah adat dan bangunan tradisional untuk materi geometri (Oktarina, Somakim, Darmawijoyo, \& Araiku, 2020), sistem penanggalan untuk teori bilangan (Prahmana \& Kusumah, 2016), serta kain songket dan batik untuk transformasi geometri (Febriani, Somakim, \& Araiku, 2020).

Terlepas dari keunggulan yang ditawarkan etnomatematika dalam pembelajaran matematika di kelas dan kekayaan budaya yang dimiliki Indonesia untuk dimanfaatkan, konsep etnomatematika ini masih belum dikenal secara luas oleh guru di Indonesia. Berdasarkan hasil survei yang dilakukan terhadap 198 responden yang merupakan guru matematika seluruh tingkat pendidikan dari seluruh bagian Indonesia melalui google form, diperoleh hasil seperti yang ditunjukkan pada Gambar 1. 


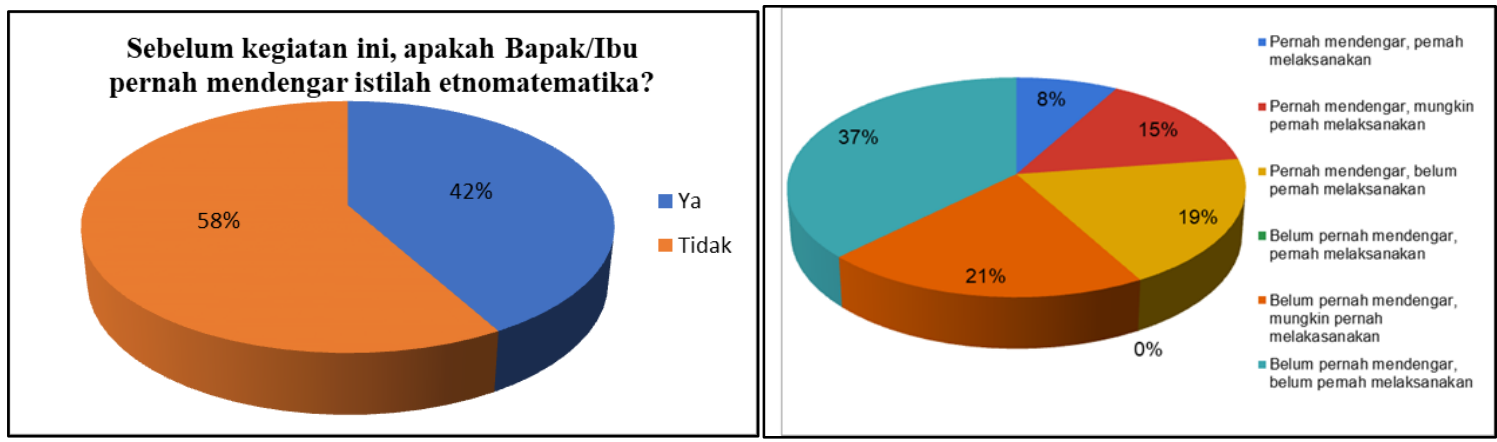

Gambar 1. Hasil survei pendahuluan

Sekitar $58 \%$ responden menyatakan belum pernah mendengar istilah etnomatematika, sedangkan sisanya pernah mendengat istilah tersebut. Jika dilihat lebih mendalam, dari $42 \%$ responden yang menjawab pernah mendengar istilah etnomatematika, terdapat 19\% menyatakan belum pernah melaksanakannya. Hal ini menandakan bahwa guru tidak atau belum mau untuk berinovasi di dalam kelas matematika yang diampunya. Selain itu, dari $42 \%$ responden, $15 \%$ diantaranya ragu jika pernah melakukan pembelajaran matematika berbasis etnomatematika di kelas. Hal ini menandakan bahwa meskipun pernah mendengar istilah etnomatematika, namun mayoritas guru belum memahami apa dan bagaimana menerapkan etnomatematika di kelasnya. Lebih lanjut, $21 \%$ dari $58 \%$ responden yang menyatakan tidak pernah mendengar istilah etnomatematika, menyatakan mungkin pernah menerapkannya di kelas yang diampu. Hal ini menandakan perlunya suatu seminar yang bertujuan untuk memperkenalkan teori pembelajaran ini kepada guru-guru matematika untuk menjadi suatu inovasi di kelas matematika yang mereka ajar.

Karena konsep etnomatematika dalam pembelajaran ini tergolong baru, maka diperlukan sosialisasi kepada guru-guru matematika untuk dalam memahami apa dan bagaimana pembelajaran berbasis etnomatematika, serta bagaimana membuat bahan ajar yang berbasis pada budaya setempat. Terdapat banyak penelitian yang menggarisbawahi pentingnya penerapan etnomatematika di kelas, mulai dari pengembangan bahan ajar (Hwan, 2000; Sowanto \& Mulyadin, 2019), hasil belajar siswa melalui etnomatematika (Herawaty, Khrisnawati, Widada, Mundana, \& Anggoro, 2020; Araiku, Somakim, \& Pratiwi, 2020), dan eksplorasi konteks budaya (Prahmana, Yunianto, Rosa, \& Orey, 2021; Massarwe, Verner, \& Bshouty, 2010). Namun belum banyak kegiatan PkM yang dilakukan berbasis pada etnomatematika. Beberapa kegiatan PkM yang dilakukan hanya terbatas pada pengenalan teori, tetapi tidak dalam penerapannya (Muchtarom, 2018). Kegiatan PkM yang dilakukan oleh Dosen Pendidikan Matematika Universitas Sriwijaya yang mengambil judul "Pendampingan Pembuatan Bahan Ajar berbasis Etnomatematika untuk Guru Matematika di Indonesia" bertujuan untuk melakukan pendampingan terhadap guru-guru matematika dalam membuat bahan ajar berbasis etnomatematika dan mengetahui respon guru terhadap kegiatan PkM yang dilaksanakan. 


\section{Metode}

Sasaran peserta yang ditargetkan dalam kegiatan PkM ini adalah sebanyak 40 guru matematika di Indonesia. Dari 40 guru tersebut, diharapkan terdapat minimal 10 bahan ajar matematika berbasis etnomatematika yang dibuat oleh guru peserta. Pendekatan yang digunakan dalam PkM ini adalah service learning, dimana kegiatan pendampingan dilakukan dalam beberapa tahap baik secara tatap maya (synchronous) maupun di tempat dan waktu yang berbeda (asynchronous), sehingga bahan ajar yang dihasilkan memiliki kualitas yang baik untuk dapat diaplikasikan di kelas (Nusanti, 2014; Susanti, et al., 2020).

Setelah pelaksanaan seluruh rangkaian kegiatan PkM, peserta diminta untuk mengisi angket respon mengenai pelaksanaan kegiatan. Angket tersebut terdiri atas lima pernyataan mengenai pelaksanaan kegiatan pendampingan, pengetahuan peserta terhadap etnomatematika, serta kesulitan yang telah atau mungkin dialami peserta dalam menerapkan etnomatematika di dalam kelasnya. Skor respon yang diberikan peserta demudian di rataratakan dan dikategorikan berdasarkan pada indikator yang ditunjukkan pada Tabel 1 (diadopsi dari Susanti, et al., 2020).

Tabel 1. Kategori skor respon peserta pendampingan

\begin{tabular}{cc}
\hline$\overline{\boldsymbol{x}}$ & Kategori \\
\hline $1 \leq \bar{x}<1,8$ & Sangat kurang \\
$1,8 \leq \bar{x}<2,6$ & Kurang \\
$2,6 \leq \bar{x}<3,4$ & Cukup \\
$3,4 \leq \bar{x}<4,2$ & Baik \\
$4,2 \leq \bar{x} \leq 5$ & Sangat baik \\
\hline
\end{tabular}

\section{Hasil dan Pembahasan}

Pelaksanaan PkM dilakukan dalam beberapa tahapan dengan jadwal dan agenda kegiatan dijelaskan pada Tabel 2.

Tabel 2. Jadwal dan Agenda Kegiatan PkM

\begin{tabular}{|c|c|c|c|}
\hline No. & Tanqgal & Agenda Keqiatan & Modal \\
\hline 1 & 4- 9 November 2020 & Pendaftaran & Gooqle form \\
\hline \multirow[t]{3}{*}{2} & 10 November 2020 & Sesi I: & Zoom conference \\
\hline & & 1) Pengertian etnomatematika & meeting dan \\
\hline & & $\begin{array}{l}\text { 2) Dasar dalam penyusunan bahan } \\
\text { ajar berbasis etnomatematika }\end{array}$ & YouTube \\
\hline 3 & 11 - 17 November 2020 & $\begin{array}{l}\text { Penugasan dan pengumpulan bahan } \\
\text { ajar matematika berbasis } \\
\text { etnomatematika }\end{array}$ & $\begin{array}{l}\text { Whatsapp dan } \\
\text { google form }\end{array}$ \\
\hline 4 & $11-20$ November 2020 & Expert Review & Whatsapp \\
\hline \multirow[t]{3}{*}{5} & 21 November 2020 & Sesi II: & Zoom conference \\
\hline & & 1) Presentasi & meeting dan \\
\hline & & 2) Pengisian angket respon & YouTube \\
\hline 6 & $22-28$ November 2020 & Revisi dan pengumpulan tugas & $\begin{array}{l}\text { Whatsapp dan } \\
\text { Google form }\end{array}$ \\
\hline 7 & 30 November 2020 & Evaluasi hasil kegiatan & $\begin{array}{l}\text { Zoon conference } \\
\text { meeting }\end{array}$ \\
\hline
\end{tabular}


Meskipun jumlah peserta yang ditargetkan adalah sebanyak 40 orang guru matematika, namun kegiatan ini berhasil menjaring sebanyak 408 guru matematika untuk berpartisipasi di dalam kegiatan PkM ini. Hal ini mungkin disebabkan istilah etnomatematika relatif baru bagi guru matematika di Indonesia (Gambar 1) sehingga banyak yang ingin memelajari teori dan penerapannya. Setelah pendaftaran, kegiatan PkM dilanjutkan dengan sesi synchronous melalui zoom conference meeting. Sesi I ini dilaksanakan pada hari Selasa, 10 November 2020 dengan mengangkat dua materi, yaitu Pengertian etnomatematika yang disampaikan oleh Dr. Somakim dari Universitas Sriwijaya dan dasar dalam penyusunan bahan ajar berbasis etnomatematika yang disampaikan oleh Prof. Marsigit dari Universitas Negeri Yogyakarta. Sesi ini dilaksanakan selama 3 jam (Gambar 2). Pada Sesi I ini, peserta diberikan pemahaman mengenai makna etnomatematika yang mengaitkan unsur matematika yang terkandung dalam nilai budaya, serta kaitannya dengan filosofi dan sejarah matematika. Selain itu, berdasarkan pemaparan Prof. Marsigit, menekankan bahwa pembuatan bahan ajar berbasis Etnomatematika dapat dikombinasikan dengan berbagai pendekatan pembelajaran seperti PMRI dan PBL. Tidak terjadi kendala yang berarti pada sesi ini.

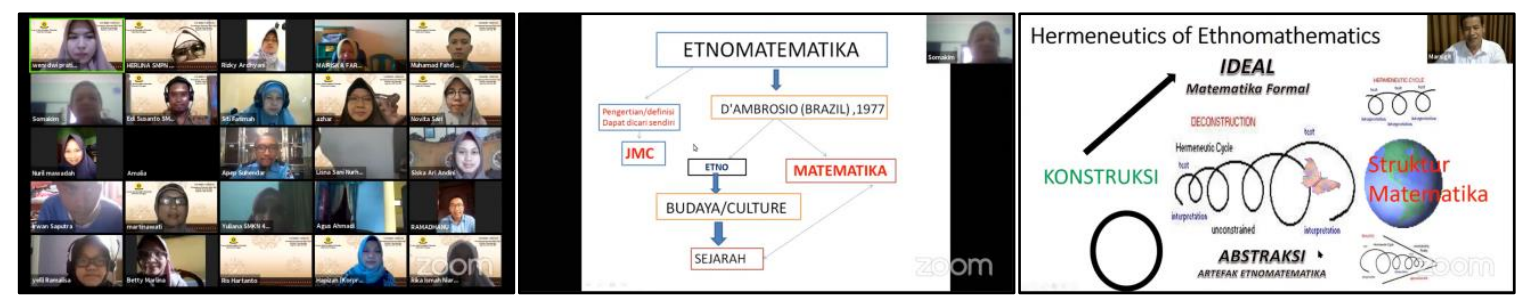

Gambar 2. Pelaksanaan sesi I

Di akhir pertemuan, panitia memberikan tugas kepada peserta untuk mengeksplor salah satu budaya di daerah mereka dan membuat bahan ajar berupa lembar kerja peserta didik (LKPD) berdasarkan budaya tersebut. LKPD ini nantinya akan diseleksi dan dibukukan untuk didaftarkan ISBN-nya. Selama masa penugasan, para peserta dipersilakan untuk bertanya kepada narasumber maupun panitia jika mengalami kesulitan dalam proses pembuatan bahan ajarnya melalui whatsapp group. Setelah masa pengerjaan tugas berakir, para peserta kemudian mengumpulkan bahan ajar yang telah dibuat melalui link google form yang telah disediakan panitia PkM. Dari 408 guru partisipan, tercatat hanya 198 peserta yang mengumpulkan bahan ajarnya untuk dievaluasi oleh narasumber pada kegiatan PkM ini. Hal ini mungkin disebabkan ada kegiatan guru di sekolah sehingga guru yang bersangkutan tidak sempat untuk membuat bahan ajar tepat waktu. Selain itu, beberapa guru membentuk kelompok sehingga satu bahan ajar dibuat oleh dua atau tiga guru peserta.

Berdasarkan hasil evaluasi, diperoleh data bahwa para peserta PkM masih melakukan beberapa kesalahan. Kesalahan pertama, banyak peserta yang masih belum mengikuti template yang diberikan oleh panitia. Padahal dalam dunia karya tulis ilmiah, mengikuti sebuah template yang telah ditentukan adalah hal mutlak yang harus dilakukan seorang penulis jika ingin karyanya diterbitkan (Susanti, et al., 2020). Kesalahan kedua yang paling sering muncul adalah dalam perancangan LKPD, peserta tidak melihat atau menggali nilai filosofis dari suatu 
budaya, melainkan hanya melihat bentuk dari sebuah objek. Sebagai contoh pada Gambar 3, salah satu peserta mengambil sebuah konteks makanan tradisional yaitu lemang, namun hanya melihat bahwa lemang tersebut berbentuk seperti tabung dan menggunakan bentuk tersebut sebagai apersepsi dalam menentukan luas permukaan tabung. Menggunakan bentuk objek suatu budaya tanpa ada melihat nilai filosofis dibalik budaya tersebut tidak dapat digolongkan sebagai etnomatematika, karena dalam penerapannya, dua dari enam dimensi etnomatematika yang perlu dipenuhi adalah terdapat nilai epistemologi dan sejarah matematis yang kemudian dikaitkan dengan pengetahuan matematika (Rosa, D'Ambrosio, Orey, Shirley, Alangui, \& Gavarrete, 2016). Hal ini juga sesuai dengan saran beberapa penelitian terdahulu, di mana diperlukan eksplorasi lebih jauh mengenai konsep matematis yang terkandung di dalam suatu budaya, tidak hanya dari bentuknya saja (Syarmadi \& Izzati, 2020; Araiku, Somakim, \& Pratiwi, 2020).
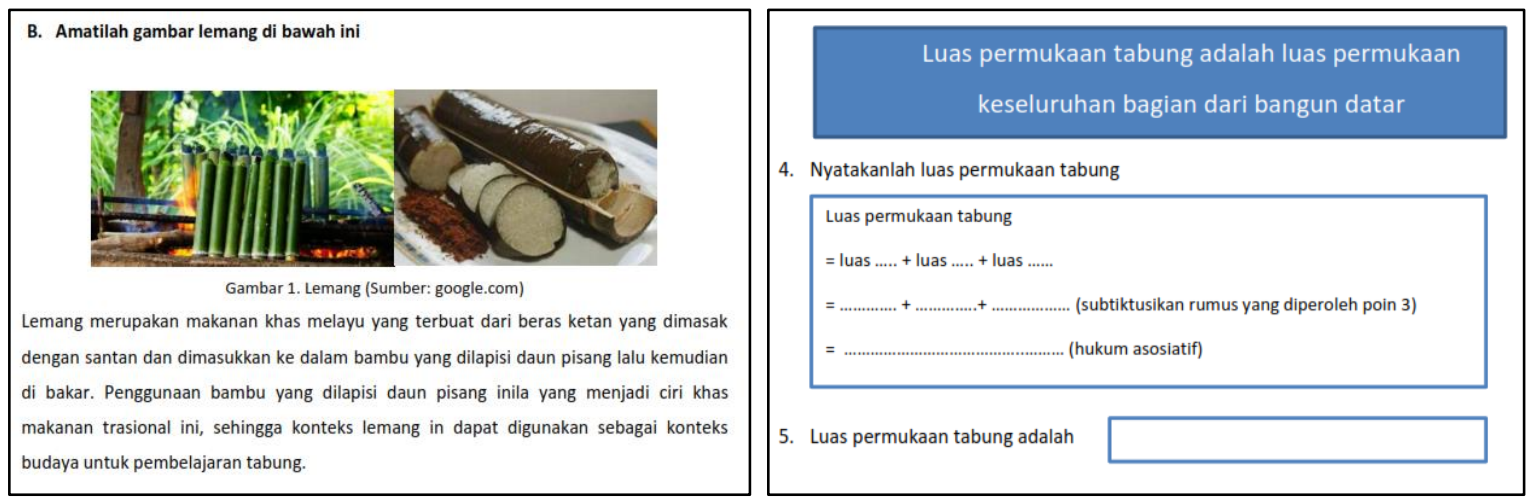

Gambar 3. Bahan ajar hanya melihat bentuk objek

Kesalahan ketiga hampir mirip dengan kesalahan kedua, di mana kegiatan-kegiatan pada LKPD telah dirancang dengan sangat baik, namun tidak didasarkan pada kebudayaan tertentu. Syarat suatu proses pembelajaran dikatakan berbasis etnomatematika adalah terdapat: (1) konteks yang relevan dengan budaya, dan (2) aktivitas yang relevan dengan budaya (Rosa, D'Ambrosio, Orey, Shirley, Alangui, \& Gavarrete, 2016). Dari kedua syarat ini, dapat disimpulkan bahwa segala proses, perangkat, bahan ajar dan media pembelajaran yang digunakan berbasis pada nilai budaya tertentu (Marsigit, Condromukti, Setiana, \& Hardiarti, 2018). Hal ini penting untuk dilakukan agar siswa didorong untuk melihat kegiatan matematika dalam konteks sosiokultural mereka sendiri, mereka menyadari bahwa prosedur dan praktik matematika terkait dengan kehidupan sehari-hari mereka (Rosa \& Orey, 2007). Sebagai contoh Gambar 4. LKPD yang dirancang salah satu peserta ini hanya melihat suatu kerangka pada sebuah bangunan modern tanpa terdapat unsur tradisi masyarakat setempat.

Kesalahan keempat yang sering dilakukan oleh peserta pendampingan adalah mereka menjabarkan filosofi atau nilai tertentu dari suatu budaya dengan cukup baik, namun kompetensi dasar yang ingin dibangun tidak didasarkan pada filosofi tersebut. Secara umum, salah satu ciri bahan ajar berbasis konteks (termasuk etnomatematika yang memanfaatkan konteks budaya) yang baik adalah keterkaitan antara konteks yang digunakan dengan konten dan aktivitas yang diberikan, sehingga sesuai dengan tujuan pembelajaran dan proses 
pembelajaran menjadi lebih bermakna (Mthethwa, 2007; Meyer, 2001; Marsigit, Condromukti, Setiana, \& Hardiarti, 2018). Sebagai contoh, Gambar 5 menunjukkan adanya penjabaran yang cukup baik dibalik pembuatan tenun Cual, seperti arti nama, jenis motif, maupun fungsinya sebagai pusaka lama. Namun, materi yang diangkat pada LKPD adalah aritmetika sosial, dimana tujuan pembelajaran adalah siswa mampu menentukan harga dari beberapa lembar kain Cual. Hal ini menandakan bahwa makna filosofi dari budaya yang diangkat belum mampu dimanfaatkan dengan baik oleh beberapa peserta pelatihan.

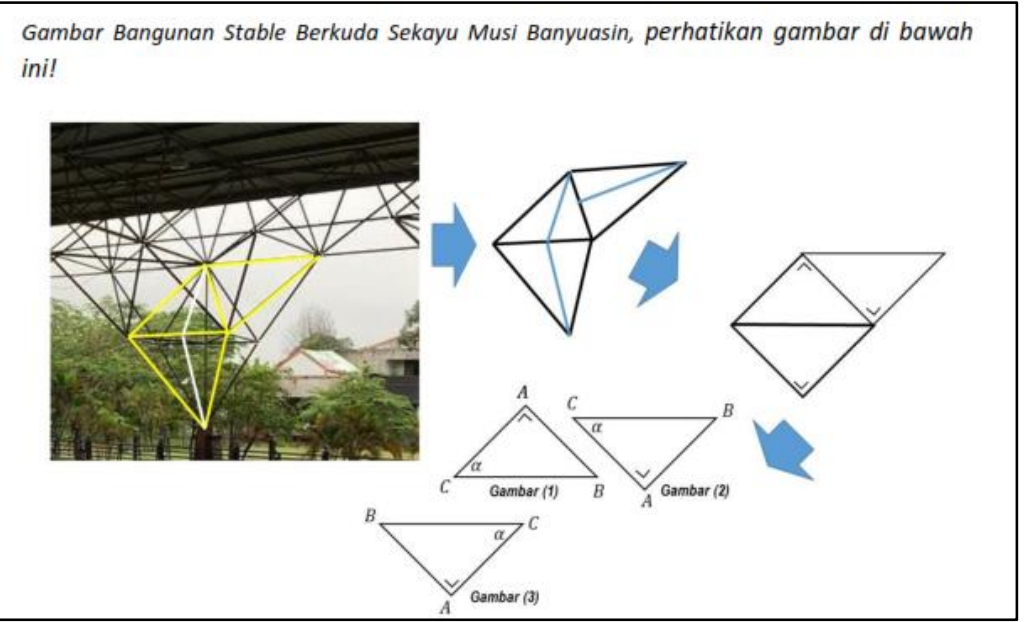

Gambar 4. Bahan ajar tidak didasarkan pada budaya daerah

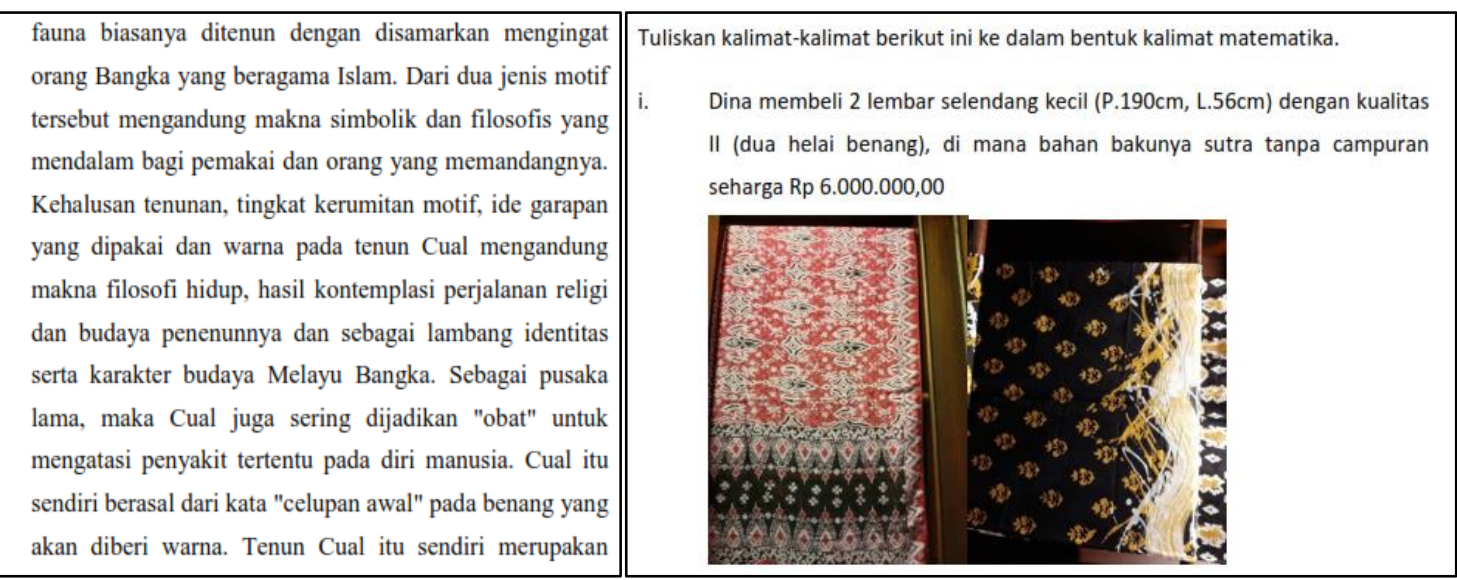

Gambar 5. Kegiatan pada bahan ajar tidak sesuai dengan filosofi budaya yang diangkat

Kesalahan kelima yang banyak dilakukan oleh peserta adalah bahan ajar tidak dielaborasi dengan baik. Secara umum, salah satu syarat LKPD yang baik adalah memenuhi syarat konstruksi, di mana LKPD tersusun secara sistematis, memiliki konten yang relevan, baik secara kebahasaaan, dan kegiatan dirumuskan secara menyeluruh (Darmodjo \& Kaligis, 1993). Pada Gambar 6 terlihat bahwa seorang peserta ingin mengangkat tema papan ludo, namun dalam langkah-langkah kegiatannya, peserta tersebut membuat kegiatan dari motif songket, di mana kegiatan ini merupakan contoh dan dibuat oleh panitia. Pada kasus ini, terlepas dari tema etnomatematika, terlihat bahwa kemampuan beberapa peserta dalam mengembangkan bahan 
ajar masih kurang baik. Secara lebih mendalam, jika hal ini terus dilakukan, maka kasus plagiarisme dalam dunia pendidikan akan tetap ada.
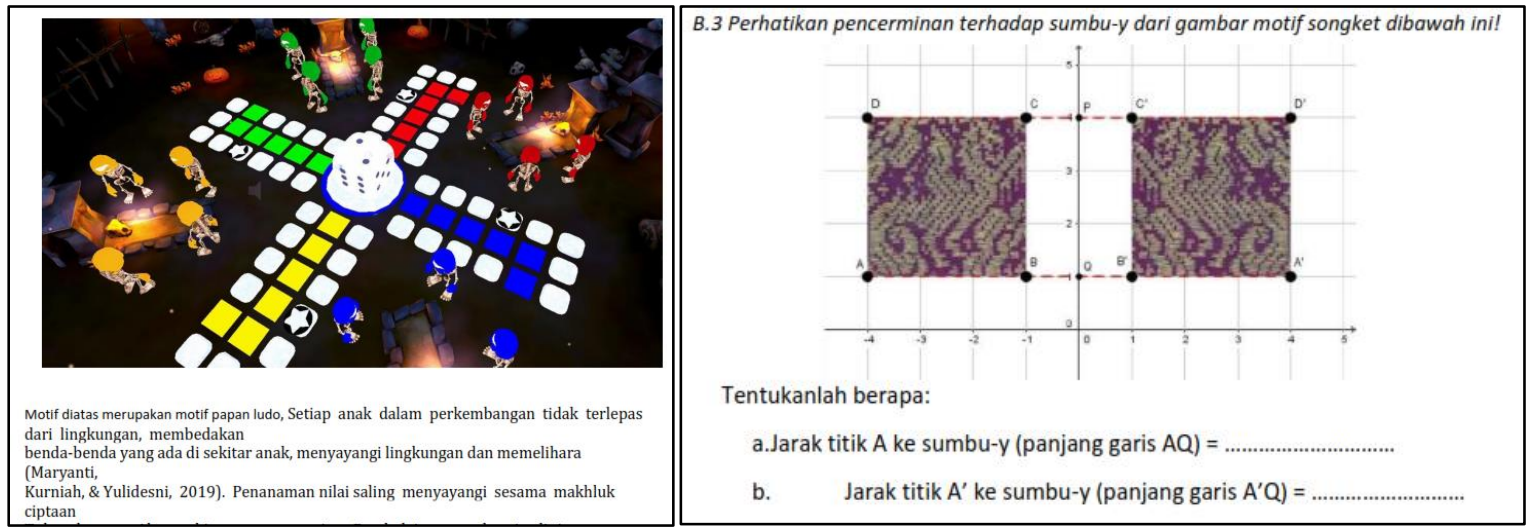

Gambar 6. Bahan ajar tidak dirancang dengan baik

Sesi synchronous kedua dilaksanakan pada hari Sabtu, 21 November 2020, di mana pada sesi ini dilakukan presentasi dari beberapa perwakilan peserta yang bahan ajarnya dinilai telah dibuat dengan baik sehingga peserta lain dapat melihatnya sebagai contoh dalam memperbaiki bahan ajarnya (Gambar 7). Pada sesi ini terpilih tiga peserta yang masing-masing mengangkat judul "Barisan Aritmetika dalam Pancawara/Hari Pasaran", "Kesebangunan dan Kekongruenan dengan Menggunakan Konteks Motif Tudung Saji Budaya Nganggung Provinsi Bangka Belitung", dan "Aplikasi Lingkaran pada Tari Khas Daerah Jambi Selampit Delapan". Dari hasil yang ditunjukkan pada sesi presentasi, para narasumber memberi komentar bahwa ketiga bahan ajar telah dibuat dengan sangat baik, di mana nilai-nilai budaya tradisional diintegrasikan dengan sangat baik dengan konsep matematika yang ingin dijelaskan pada bahas ajar tersebut.

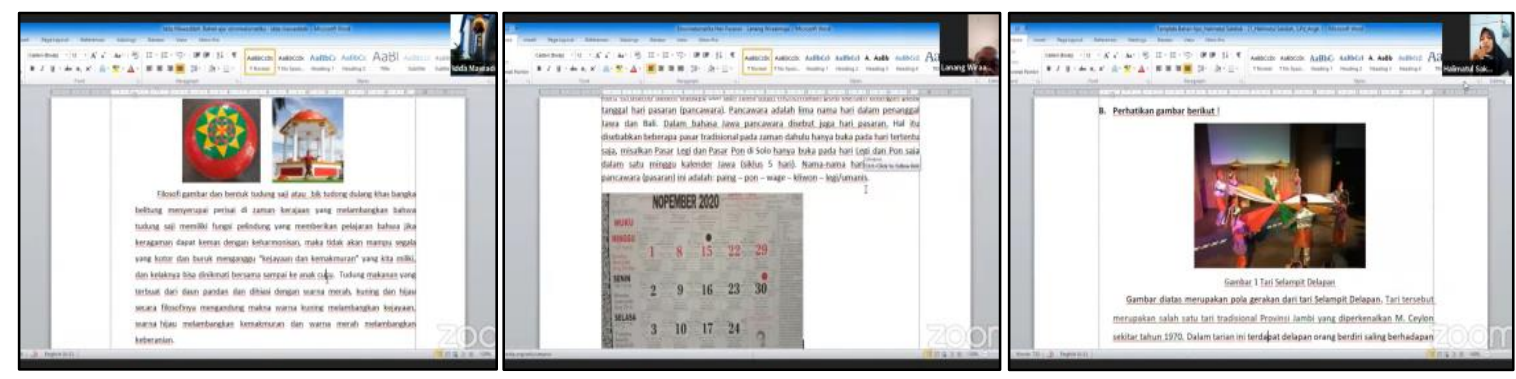

Gambar 7. Presentasi peserta pendampingan

Hasil revisi yang diterima oleh panitia adalah sebanyak 78 bahan ajar. Angka ini jauh berkurang dibandingkan dengan bahan ajar yang dikumpulkan di awal. Beberapa faktor dapat menjadi penyebab berkurangnya jumlah bahan ajar ini adalah kesibukan para peserta sebagai guru sehingga tidak dapat mengumpulkan hasil revisi secara tepat waktu. Selain itu, terdapat beberapa bahan ajar dengan tingkat kemiripan yang tinggi, sehingga beberapa bahan ajar ditolak untuk diterbitkan menjadi buku. Pada akhir sesi II, peserta diminta untuk mengisi angket respon mengenai kegiatan pendampingan, pengetahuan peserta terhadap etnomatematika, dan kesulitan dalam mengimplementasikan etnomatematika di dalam kelas. Hasil analisis dari respon peserta ini dapat dilihat pada Tabel 3 berikut. 
Tabel 3. Hasil analisis respon peserta pendampingan

\begin{tabular}{|c|c|c|c|}
\hline No & Pernyataan & $\begin{array}{l}\text { Skor rata- } \\
\text { rata }\end{array}$ & Kategori \\
\hline 1 & Waktu pelaksanaan & 4,31 & sangat baik \\
\hline 2 & Penguasaan materi narasumber secara keseluruhan & 4,73 & sangat baik \\
\hline 3 & Pelayanan yang diberikan panitia & 4,43 & sangat baik \\
\hline 4 & Isi materi yang disampaikan & 4,63 & sangat baik \\
\hline 5 & Relevansi tema Webop dengan profesi saya & 4,66 & sangat baik \\
\hline 6 & Kegunaan Webop terhadap bidang pekerjaan saya & 4,73 & sangat baik \\
\hline 7 & $\begin{array}{l}\text { Pemahaman terhadap bahan ajar berbasis } \\
\text { etnomatematika }\end{array}$ & 4,09 & baik \\
\hline 8 & $\begin{array}{l}\text { Pengetahuan dalam menemukan konteks } \\
\text { etnomatematika }\end{array}$ & 4,01 & baik \\
\hline 9 & $\begin{array}{l}\text { Pengetahuan dalam menganalisis konteks } \\
\text { etnomatematika dengan konten matematika }\end{array}$ & 3,95 & baik \\
\hline 10 & $\begin{array}{l}\text { Pengetahuan mengenai penyusunan bahan ajar berbasis } \\
\text { etnomatematika }\end{array}$ & 3,94 & baik \\
\hline 11 & $\begin{array}{l}\text { Kemampuan mengidentifikasi karakteristik budaya dan } \\
\text { sejarah di daerah masing-masing yang dapat digunakan } \\
\text { untuk menyusun bahan ajar berbasis etnomatematika }\end{array}$ & 3,93 & baik \\
\hline 12 & $\begin{array}{l}\text { Kemampuan untuk menghubungkan konteks budaya dan } \\
\text { sejarah dengan konten matematika }\end{array}$ & 3,93 & baik \\
\hline 13 & $\begin{array}{l}\text { Kemampuan untuk menyusun bahan ajar berbasis } \\
\text { etnomatematika }\end{array}$ & 3,81 & baik \\
\hline 14 & $\begin{array}{l}\text { Kemampuan untuk menggunakan bahan ajar berbasis } \\
\text { etnomatematika dalam pembelajaran di kelas }\end{array}$ & 3,79 & baik \\
\hline 15 & $\begin{array}{l}\text { Pemahaman mengenai cara menentukan konteks } \\
\text { etnomatematika dari budaya dan sejarah daerah tertentu }\end{array}$ & 3,89 & baik \\
\hline 16 & $\begin{array}{l}\text { Pemahaman mengenai cara menyusun bahan ajar } \\
\text { berbasis etnomatematika }\end{array}$ & 3,84 & baik \\
\hline 17 & $\begin{array}{l}\text { Pemahaman mengenai cara menggunakan bahan ajar } \\
\text { berbasis etnomatika di kelas }\end{array}$ & 3,88 & baik \\
\hline 18 & $\begin{array}{l}\text { Efektivitas penggunaan bahan ajar berbasis } \\
\text { etnomatematika dalam pembelajaran di kelas/sekolah }\end{array}$ & 3,89 & baik \\
\hline 19 & $\begin{array}{l}\text { Inisiatif/kesadaran diri dalam menyusun bahan ajar } \\
\text { berbasis etnomatematika }\end{array}$ & 3,91 & baik \\
\hline 20 & $\begin{array}{l}\text { Inisiatif/kesadaran diri dalam menggunakan bahan ajar } \\
\text { berbasis etnomatematika di kelas/disekolah }\end{array}$ & 3,91 & baik \\
\hline 21 & $\begin{array}{l}\text { Kebudayaan dan sejarah di daerah yang banyak } \\
\text { mendukung dalam pembuatan bahan ajar berbasis } \\
\text { etnomatematika }\end{array}$ & 3,96 & baik \\
\hline 22 & $\begin{array}{l}\text { Efisiensi dan efektivitas pengaturan waktu dalam } \\
\text { melaksanakan penggunaan bahan ajar berbasis } \\
\text { etnomatematika di Sekolah }\end{array}$ & 3,82 & baik \\
\hline
\end{tabular}

Berdasarkan hasil yang diperoleh pada Tabel 3, dapat dilihat bahwa nilai rata-rata respon peserta terhadap indikator pelaksanaan pendampingan adalah 4,55 (nomor $1-7$ ), di mana berdasarkan indikator pada Tabel 1 , pelaksanaan pendampingan masuk ke dalam kategori sangat baik. Berdasarkan respon peserta tersebut, dapat disimpulkan bahwa pelaksanaan kegiatan PkM tergolong cukup baik. Selain itu, bahan ajar yang dikumpulkan adalah sebanyak 78 buah, jauh lebih banyak dibandingkan dengan target tim PkM yaitu 10 buah. Pada indikator 
pemahaman guru mengenai etnomatematika (nomor 8 - 18), nilai rata-rata respon peserta adalah sebesar 3,9, sehingga masuk ke dalam kategori kategori baik. Meskipun demikian, beberapa hal perlu untuk lebih diperhatikan, misal pada indikator "Kemampuan untuk menyusun bahan ajar berbasis etnomatematika" yang memeroleh skor rata-rata 3,81 dan "Kemampuan untuk menyusun bahan ajar berbasis etnomatematika" yang mendapatkan skor 3,79. Hal ini berarti bahwa kemampuan guru dalam menyusun dan menerapkan bahan ajar berbasis etnomatematika harus lebih ditingkatkan dengan cara membiasakan diri untuk melakukan kedua hal tersebut dalam pembelajaran matematika di kelas. Lebih lanjut, pada indikator mengenai kesulitan dalam menerapkan bahan ajar berbasis etnomatematika (nomor 19 - 22), nilai rata-rata yang diperoleh adalah 3,9, sehingga guru harus dapat meluangkan waktu lebih terutama dalam mengeksplorasi budaya setempat sehingga nilai budaya yang diangkat sesuai dengan materi yang diajarkan.

\section{Kesimpulan}

Berdasarkan hasil kegiatan pendampingan yang dilakukan, dapat disimpulkan bahwa seluruh rangkaian kegiatan termasuk dalam kategori sangat baik (dengan rata-rata sebesar 4,55). Pengetahuan peserta mengenai etnomatematika dapat digolongkan baik. Hal ini dibuktikan dengan respon peserta sebesar 3,9 dan jumlah bahan ajar yang dikumpulkan setelah revisi berdasarkan saran narasumber adalah sebanyak 78 buah (melebihi target 10 buah). Namun demikian, terdapat beberapa kasalahan yang dilakukan guru dalam membuat bahan ajar matematika berbasis etnomatematika, antara lain: (1) bahan ajar yang dibuat tidak sesuai template yang ditentukan, (2) bahan ajar tidak memanfaatkan filosofi/nilai budaya, namun hanya melihat bentuk objek, (3) bahan ajar tidak didasarkan pada budaya tertentu, (4) materi dan langkah pembelajaran tidak sesuai dengan filosofi budaya yang diangkat, dan (5) kegiatan tidak dirancang dengan baik dan berpotensi plagiat. Dari hasil PkM ini, akan dibuat sebuah buku panduan yang pembuatan bahan ajar matematika berbasis etnomatematika, di mana di dalam buku tersebut akan menyoroti beberapa temuan PkM ini. Selain itu, saran yang dapat diberikan adalah bahwa guru perlu untuk memperbaiki manajemen waktu dalam mengekplorasi dan mengembangkan bahan ajar tersebut, sehingga kesalahan-kesalahan yang telah diidentifikasi dapat dihindari.

\section{Ucapan Terima Kasih}

Tim pengadian kepada masyarakat kegiatan pendampingan pembuatan bahan ajar berbasis etnomatematika untuk guru matematika di Indonesia mengucapkan terima kasih kepada Universitas Sriwijaya yang telah mendanai kegiatan ini melalui dana PNBP skema aplikasi IPTEK dan pengembangan budaya lokal, No: 0018.073/UN.9/SB3.LP2M.PM/2020. Tim PkM juga mengucapkan terima kasih kepada seluruh panitia, narasumber, dan peserta yang telah terlibat dalam kegiatan ini. 


\section{Referensi}

Achor, E. E., Imoko, B. I., \& Uloko, E. S. (2009). Effect of Ethnomathematics Teaching Approach on Senior Secondary Student's Achievement and Retention. Locus Educational Research and Review, 4(8), 385-390. Diakses di: https://ssrn.com/abstract=2618193

Araiku, J., Somakim, \& Pratiwi, W. D. (2020). Ethnomathematics: Utilizing South Sumatra's cultures to emphasize prospective teachers' creativity in creating mathematical problem. Journal of Physics: Conference Series, 1581(1), 1-8.

Arisetyawan, A., Suryadi, D., Herman, T., Rahmat, C., \& No, J. D. (2014). Study of Ethnomathematics: A lesson from the Baduy Culture. International Journal of Education and Research, 2(10), 682 - 688.

Ascher, M. (1991). Ethnomathematics: A Multicultural View of Mathematical Ideas. Pacific Grove, California: Brooks/Cole.

Brand, \& Chernoff. (2015). The Importance of Ethnomathematics in the Math Class. Ohio Journal of School Mathematics, 7, 31-36.

D'Ambrosio, U. (1985). Ethnomathematics and its place in the history and pedagogy of mathematics. For the learning of Mathematics, 5(1), 44-48.

Darmodjo, H., \& Kaligis, J. (1993). Pendidikan IPA II. Jakarta: Dirjen Dikti.

Febriani, K., Somakim, \& Araiku, J. (2020). Student's response to realistic mathematics learning with the context of Palembang songket. Journal of Physics: Conference Series, 1-7.

Francois, K. (2012). Ethnomathematics in a European Context: Towards an Enrichment Meaning of Ethnomathematics. Journal of Mathematics and Culture, 6(1), 191-208.

Garegae, P. (2008). Conceptualizing Ethnomathematics as a Bridge between Peace and Conict: The Case of Cultural Artefacts. The Fifteenth International Conference on Learning, 1-15 .

Gerdes, P. (1994). Reflection on ethnomatematics. For the Learning of Mathematics, 14(2), 19-21.

Herawaty, D., Khrisnawati, D., Widada, W., Mundana, P., \& Anggoro, A. F. (2020). The cognitive process of students in understanding the parallels axiom through ethnomathematics learning. Journal of Physics: Conference Series, 1470(1), 1-7.

Hwan, K. S. (2000). Development of Materials for Ethnomathematics in Korea. In H. Selin, Mathematics Across Cultures. Science Across Cultures: The History of Non-Western Science (Vol. 2, pp. 455-465). Dordrecht: Springer.

Jenni, L. (2007). Foundation in Ethnomathematics for Prospective Elementary Teachers. The Journal of Mathematics and Culture, 2(1), 1-19.

Kusuma, D. A., Dewanto, S. P., Ruchjana, B. N., \& Abdullah, A. S. (2017). The role of ethnomathematics in West Java (a preliminary analysis of case study in Cipatujah). Journal of Physics: Conf. Series, 893(012020), 1-8.

Leng, N. W. (2006). Effects of an Ancient Chinese Mathematics Enrichment Programme on Secondary School Students Achievement in Mathematics. International Journal of Science and Mathematical Education, 4(1), 485-511.

Marsigit, Condromukti, R., Setiana, D. S., \& Hardiarti, S. (2018). Pemngembangan Pembelajaran Matematika berbasis Etnomatematika. Seminar Nasional Pendidikan Matematika Etnomatnesia (pp. 20 - 38). Yogyakarta: Universitas Sarjanawiyata Tamansiswa.

Massarwe, K., Verner, I., \& Bshouty, D. (2010). Ethnomathematics and Multi-Cultural Education: Analysis and Construction of Geometric Ornaments. Journal of Mathematics \& Culture, 5(1), 344 $-360$.

Meyer, M. (2001). Mathematics in Context. Chicago: Education Development Center, Inc.

Mthethwa, T. M. (2007). Teacher's Views on the Role of Context in Mathematical Literacy. Johannesburg: WitsETD.

Muchtarom, A. (2018). PPM KKNM Integratif Penerapan Etnomatematika dan Etno-informatika untuk Pemetaan Budaya Sunda di Kecamatan Jatinangor. Retrieved 12 9, 2020, from Fakultas MIPA Universitas Padjadjaran: http://www.fmipa.unpad.ac.id/fix/2018/11/26/ppm-kknm-integratifpenerapan-etnomatematika-dan-etno-informatika-untuk-pemetaan-budaya-sunda-dikecamatan-jatinangor/

Nurhasanah, F., Kusumah, Y., \& Sabandar, J. (2017). Concept of triangle: Examples of mathematical abstraction in two different contexts. International Journal on Emerging Mathematics Education, $1(1), 53-70$. 
Nusanti, I. (2014). Strategi Service Learning: Sebuah Kajian untuk Mengembangkan Kegiatan Pembelajaran. Jurnal Pendidikan dan Kebudayaan, 20(2), 251 - 260.

Oktarina, D., Somakim, Darmawijoyo, \& Araiku, J. (2020). Learning design of planes using context culture traditional house Bengkulah. Journal of Physics: Conference Series, 1480, 1-6.

Prahmana, R. C., \& Kusumah, Y. S. (2016). The hypothetical learning trajectory on research in mathematics education using research-based learning. Pedagogika, 123(3), 42 - 54.

Prahmana, R. C., Yunianto, W., Rosa, M., \& Orey, D. C. (2021). Ethnomathematics: Pranatamangsa System and The Birth-Death Ceremonial in Yogyakarta. Journal on Mathematics Education, 12(1), $93-112$.

Rosa, M., \& Orey, D. C. (2007). Cultural assertions and challenges towards pedagogical action of an ethnomathematics program. For the Learning of Mathematics, 27(1), $10-16$.

Rosa, M., D'Ambrosio, U., Orey, D. C., Shirley, L., Alangui, W. V., \& Gavarrete, M. E. (2016). Current and Future Perspectives of Etnomathematics as a Program. Hamburg: Springer.

Sowanto, \& Mulyadin, E. (2019). Developing of teaching materials for junior high school students based on ethnomathematics on traditional woven cloth (Tembe Nggoli) of Mbojo tribe. Journal of Physics: Conference Series, 1280(1), 1-6.

Susanti, E., Aisyah, N., Hiltrimartin, C., Hartono, Y., Somakim, Meryansumayeka, et al. (2020). Pendampingan Penulisan Artikel Ilmiah Penelitian Tindakan Kelas bagi Guru Matematika. Jurnal Anugerah, 2(2), 99 - 106.

Susanti, E., Hitrimartin, C., Aisyah, N., Hartono, Y., Hapizah, Somakim, et al. (2020). Teknik Penulisan Artikel IImiah Penelitian Tindakan Kelas di Era New Normal. Palembang: CV. Bening Media Publishing.

Syarmadi, \& Izzati, N. (2020). Ethnomathematics Exploration of Jong Sailboat Shape As a Traditional Game in the Riau Islands. Numerical: Jurnal Matematika dan Pendidikan Matematika, 4(2), 111122.

Tanujaya, B., Prahmana, R. C., \& Mumu, J. (2017). Mathematics instruction, problems, challenges, and opportunities: A case study in Manokwari regency, Indonesia. World Transactions on Engineering and Technology Education, 15(3), 287 - 291.

Young, J. (2017). Technology integration in mathematics education: Examining the quality of metaanalytic research. International Journal on Emerging Mathematics Education, 1(1), 71-86. 